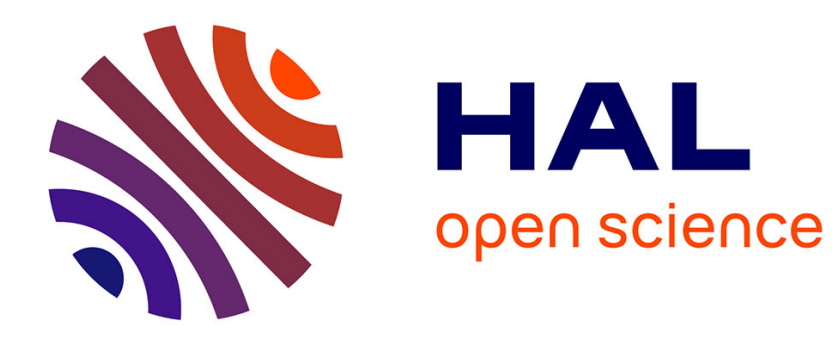

\title{
Optical characterization of the facets of a heliostat
}

\author{
J.A. Avellaner
}

\section{To cite this version:}

J.A. Avellaner. Optical characterization of the facets of a heliostat. Revue de Physique Appliquée, 1980, 15 (2), pp.169-173. 10.1051/rphysap:01980001502016900 . jpa-00244712

\section{HAL Id: jpa-00244712 https://hal.science/jpa-00244712}

Submitted on 1 Jan 1980

HAL is a multi-disciplinary open access archive for the deposit and dissemination of scientific research documents, whether they are published or not. The documents may come from teaching and research institutions in France or abroad, or from public or private research centers.
L'archive ouverte pluridisciplinaire HAL, est destinée au dépôt et à la diffusion de documents scientifiques de niveau recherche, publiés ou non, émanant des établissements d'enseignement et de recherche français ou étrangers, des laboratoires publics ou privés. 


\title{
Optical characterization of the facets of a heliostat
}

\author{
J. A. Avellaner \\ INITEC, Energia, Madrid, Spain \\ (Reçu le 25 septembre 1979, révisé le 16 novembre 1979, accepté le 19 novembre 1979)
}

\begin{abstract}
Résumé. - Cette étude est principalement destinée à la description des méthodes d'essai applicable aux panneaux réflecteurs des héliostats (facettes) d'une centrale électrosolaire à tour. Elles permettent de mesurer leurs performances optiques, c'est-à-dire, de déterminer les irrégularités de la surface du verre (microscopique et macroscopique), les caractéristiques du dépôt d'argent et les irrégularités de forme. Ce résultat est obtenu en spécifiant un premier groupe de paramètres pour sélectionner les composants et les procédés de fabrication.
\end{abstract}

\begin{abstract}
This study is mainly aimed at describing the testing methods for qualifying the heliostat reflector panels (facets) of a central tower type solar power station from an optical point of view, that is, determination of glass surface irregularities (both microscopic and macroscopic), silver deposition methods and shape distorsions, in order to obtain a set of specifiable parameters applicable to both the selecting process of heliostat components and manufacturing procedures.
\end{abstract}

1. Introduction. - A solar power station of central tower concept is composed of a series of tracking mirrors (heliostats) wich aim and concentrate the solar direct radiation onto a receiver, located on top of a tower, that transfers the radiant energy to a heat transfer fluid wich is used in a thermodynamic engine.

In order to maintain the receiver radiation and convective losses to a minimum a relatively small receiver is required, and consequently a small heliostat image. On the other hand, from an economic point of view, the biggest heliostat is desirable. Bearing in mind the above mentioned conditions and the fact that the sun beam subtends an angle of $32^{\prime}$, wich produces an increase of heliostat image size, it follows that a focusing heliostat is necessary.

The best theoretical solution for such a type of heliostat is the use of a spherical cap, but due to manufacturing problems, the reflective surface is divided in a given number of reflector panels (facets) wich are placed tangent to the theoretical spherical cap. The heliostat image in this case will be formed from the overlapping of individual images of each facet. If a smaller image size is required, the facets can be focused also, either spherically or in cylindral shape. The curvature of the facets is normally done by fixing the reflective surface (back silvered glass mirrors) onto a substrate rigid enough to withstand wind and weigth load and with special characteristics to withstand environmental conditions such as daily thermal cycling, moisture, UV radiation, etc.
The quality of the heliostat image, both size and energy distribution strongly depends on the optical quality of the facets, hence the analysis of the factors contributing to the facet image size is of a paramount importance.

2. Classification of the dispersing factors. - The imperfections which cause an increase in the natural dispersion of the incident beam may be classified into three types on the basis of the geometric dimensions under study and in a parallel way with reference to the fields of responsibility assignable to each stage of manufacturing process :

a) Microscopic imperfections essentially due to the deposition quality of the reflective substrate. Thus, the electro-silvering has better size-grading and covering capacity than chemically deposited silver. Other factors which affect, to a lesser degree, are density of deposition $\left(\mathrm{mg} / \mathrm{m}^{2}\right)$ and even glass anisotropy.

b) Macroscopic imperfections essentially caused by the quality of the glass manufacturing process as regards the geometric aspect or surface finishing. In this connection, the use of float glass is being brought into general use in substitution for sheet glass.

c) Deviations from theoretical shape due to imperfections introduced during from the construction of the facet which result from : warping or imperfections of the supporting structure, lack of stiffness and even dimensional degradation of the assembly, with time. 
3. Characterization of dispersions. - From the point of view of the energy balance of the plant and even as a parameter for a design and construction specification, the most practical criterion is to characterize the facet by the use of standard deviations from the theoretical surface (flat, cylindrical, or spherical, normally). This characterization, assuming that the errors in facet manufacture are random with normal distribution, is a reasonable assumption. In this way, each stage will have its maximum limit in the manufacture and it shall be possible to assign a simple optical parameter to the whole facet.

In short, an adjustment to a normal distribution is adopted and each factor is characterized by its standard deviations.

4. Testing methods. - Two testing methods are established for the purpose of characterizing the aforementioned factors : the first method consists in studying directly the image projected upon an assembly (Energy Method) and the second one is based on the analytical study of the factors (Analytical Method), in such a way that both methods must be supplementary to permit a unification. Both procedures are studied below, as well as the applicable methods of analysis.

4.1 GLOBAL STUDY OF THE IMAGE (ENERGY METHOD). -4.1 .1 Image of the sun by reflection on a test target. - This method is based in the analysis of the energy distribution of the produced heliostat image onto a target. This analysis can be made by two possible ways, first using a grid of photoelements and second by means of a densitometric study of the negative of a photography of image.

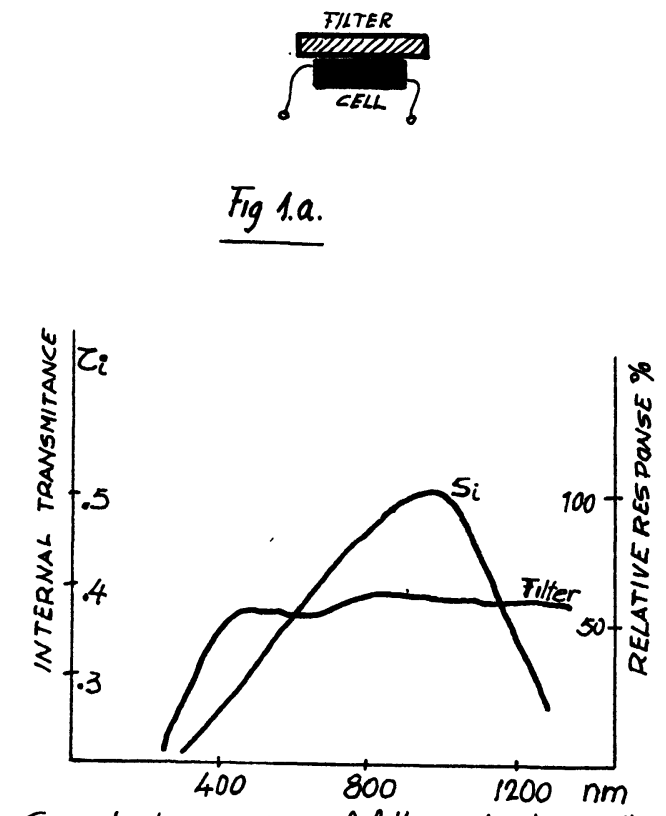

Spectral response of filter and siliconcell
Both systems require a detailed measurement of energy distribution over the solar disk as long as the image is the result of convoluting the solar disk distribution with the normals to the facet surface [1].

4.1.1.1 Target provided with photosensitive elements. - This classical testing method requires the study of the photocell spectral response and the obtention of a calibration. Normally, silicon cells are used, it being necessary to attenuate the incident energy (1 to 10 suns), so as not to saturate the photocell, which can be achieved with the use of two methods :

a) Attenuation with neutral filters applied to the solar spectrum (Fig. 1a).

$b$ ) Negative polarization of the photocell so as to take the working point to the linear area (Fig. 1b).

The degree of analysis which can be obtained with this method depends on the number of photocells arranged on the target, a high velocity being necessary on taking the data. A typical scanning time lies between five to ten seconds.

4.1.1.2 Microdensitometry study. - The method is based [2] in the proportionality between the logarithm of exposure $E$, being $E$ the energy per unit area incident at each point on a photosensitive surface (film), and the transmitance of the developed film $(\tau)$.

This correlation is normally plotted in the so called Hurter-Driffield curve wich represents in abscissas the logarithm of the exposure and in ordinates the transmitance of developed film (Fig. 2a). The slope in the linear region of the curve is the $\gamma$ value of the film, being a measure of the contrast of a film (the bigger the $\gamma$ value the higher the contrast).

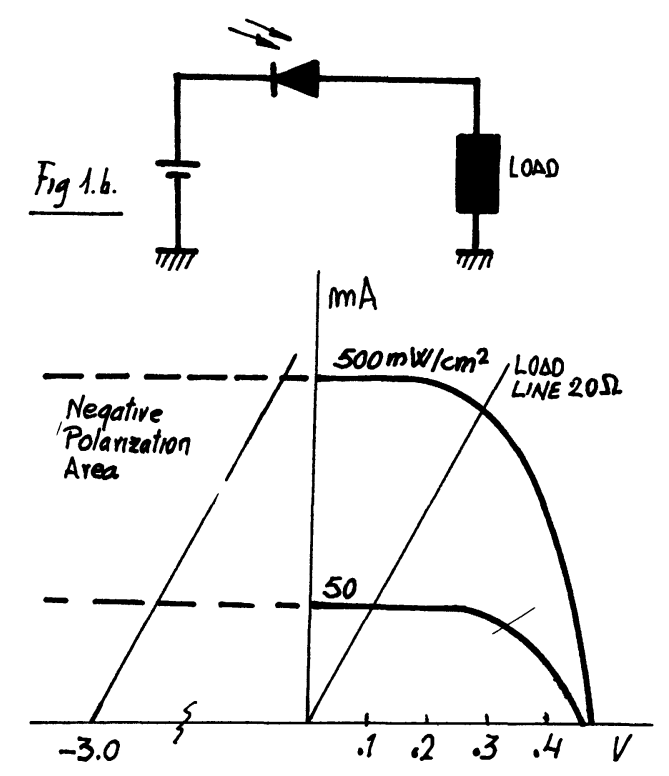

Fig. 1. - a) A photocell filter mounted and spectral response characteristics of filter and silicon cells. $h)$ Negative polarization and typical output characteristic silicon cells. 


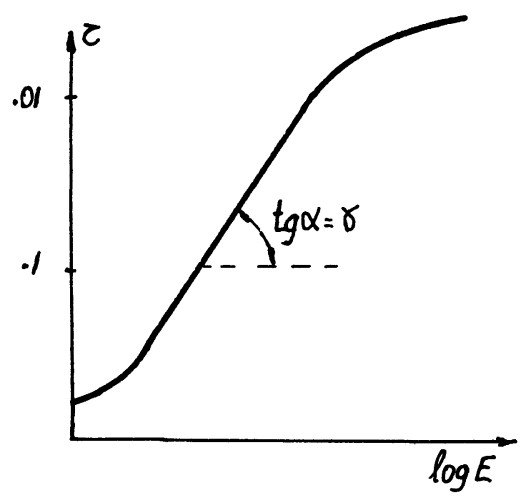

fig.2a. H\&D curve.

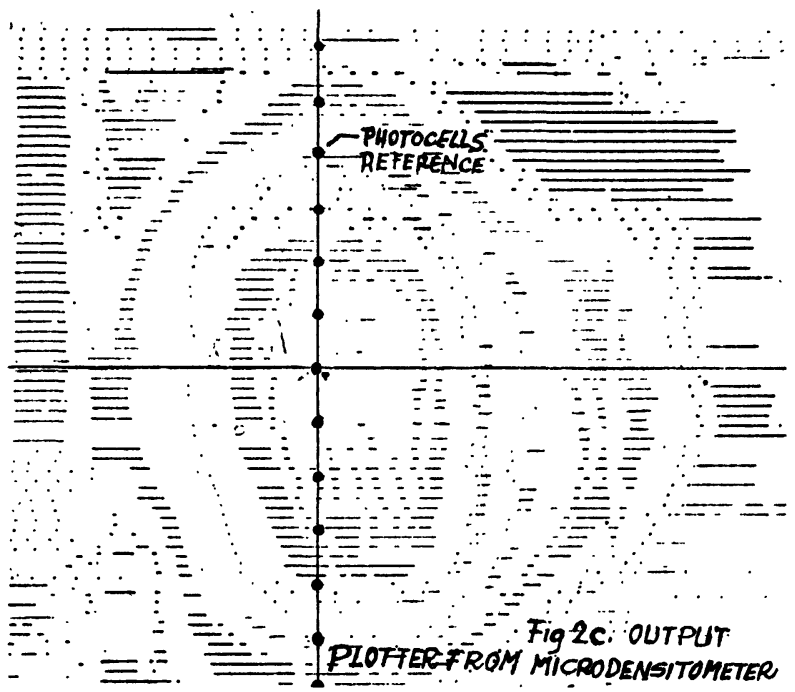

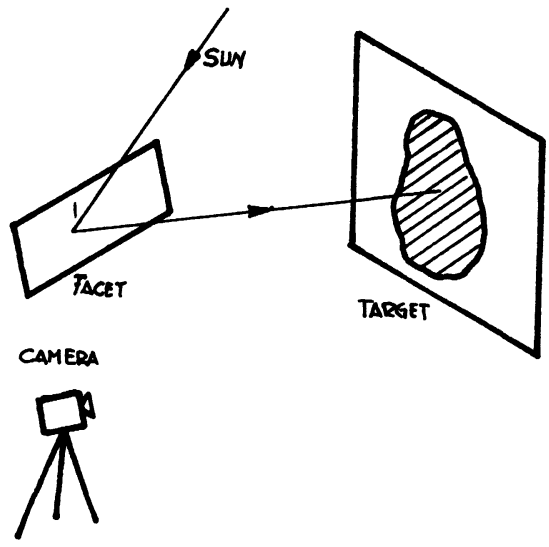

Fig.2b. Assembling.

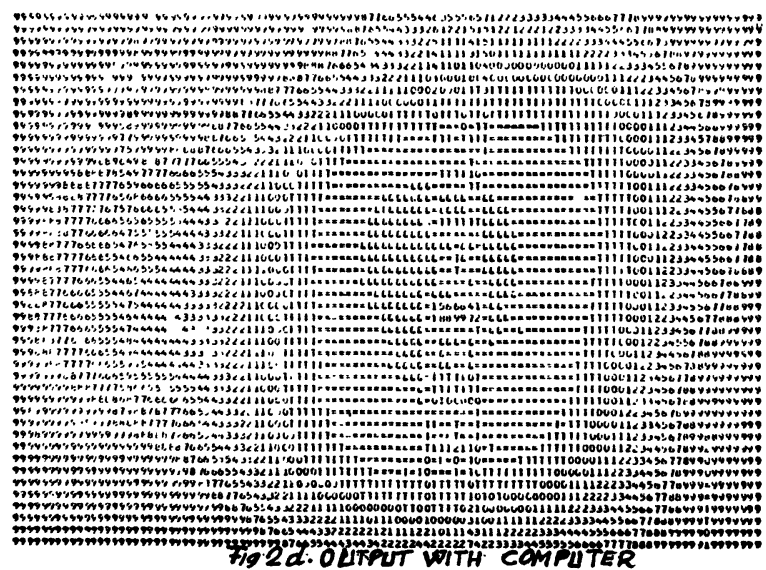

Fig. 2. - Photography and study by microdensitometry. a) H \& D curve. b) Assembling. c) Plotter output. d) Computer output.

In addition to this, there are instruments (microdensitometers) capable of discriminating very small differences in transmitance (up to 64000 levels within $50 \mu \mathrm{m})$.

The use of the properties of a film (Hurter-Driffield curve) and the characteristics of microdensitometers give a good method for qualifying images.

The main disadvantage of this method lies in the necessity of working in the linear region of $\mathrm{H}$ and $\mathrm{D}$ curve, wich is normally difficult. In order to obviate this disadvantage, a method combined with the preceding one is used, that is, we simultaneously take one row, at least, of photosensitive elements as patterns of the grey range obtained during the photographic process (Fig. $2 b, 2 c, 2 d$ ).

In any case, the analysis by microdensitometry permits making a qualitative study which is very useful for the characterization of a facet and it provides a degree of discrimination which cannot be attained with the 4.1.1.1 test ( $>10000$ points versus 1000 points, for instance).
4.1.2 Direct photograph of the reflected beam. This method is intended to investigate the contribution on the image from each zone of the facet
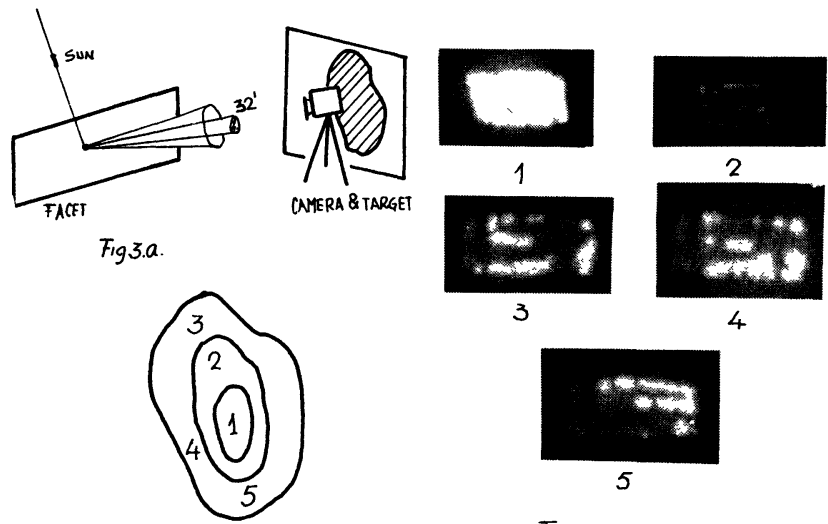

Fig 3.b. 4

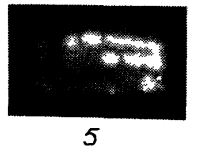

Fig. 3.c.

Fig. 3. - Direct study of the reflected beam. a) Field mounted. b) Image onto target. c) Obtained photography for the above mentioned points. 
through the study by microdensitometry of the photograph taken from the target in the direction of the heliostat (it is the method used for the study of the solar disk distribution). A series of photographs have to be taken from various points of the image and, for the purpose of having them geometrically referenced, a simultaneous photograph of the location of the main camera within the image is necessary (Fig. $3 a$, $3 b, 3 c)$. Because of the great intensity to which the film will be subjected, the use of an attenuator filter with a flat response is required.

4.2 AnAlytical STUDY. - This study is aimed at establishing a series of tests to characterize each of the factors, the responsibility for the manufacturing process of the facets being assigned to a certain manufacturer.

4.2.1 Microscopic arrangements. - As stated before, silvering is the main factor responsible for the dispersion at a microscopic scale. The test $[3,4]$ designed to study this effect consists in obtaining a coherent beam, better than 1 mrad., so as to study the dispersion generated in a reflection on the test mirror.

The reflection area must be smaller than $\frac{1}{2} \lambda$ ( $\lambda=$ wavelength) of the macroscopic imperfections, for which an initial diaphragm is provided. Once the coherent beam is conformed and reflected, the energy gathered is studied in a detector with a variable opening (tungsten-silicon is used as detector couple). The arrangement carried out by the INO [5] permits a study for variable incidence angles.

Once the reflectance is calculated for various openings, it is adjusted to a normal distribution, thus obtaining the standard deviation.

The attached table shows the results of some tests and the adjustment done [6].

4.2.2 Macroscopic arrangements. - The methods applicable to this type of study are very numerous and only two of them are described. The test is performed, in one case, with glass sample and, in the other, with a mirror sample. The dimension required for the test piece is $2 \lambda$ at least.

As we have already stated, the dispersions at this scale are mainly due to the glass manufacturing process.
4.2.2.1 Mechanical. - A geometrical measurement is performed with the use of displacement gages with an accuracy of $0.005 \mathrm{~mm}$. From the measurements made we obtain the average wave
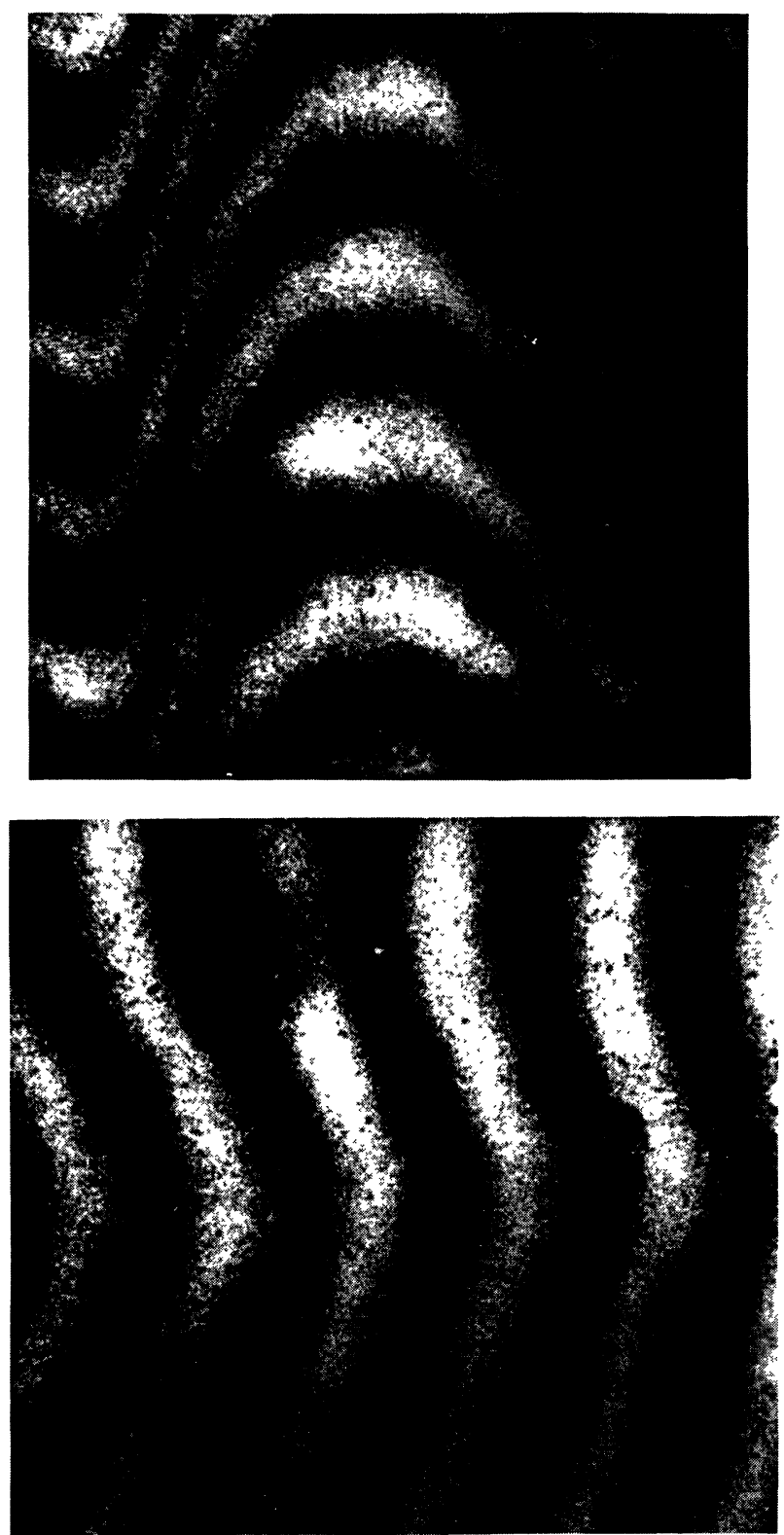

Fig. 4. - Moiré interferometry longitudinal (2.5 bands) and transversal ( 0.6 band).

Table I. - Parameters of reflexion for two manufacturer. $\theta$ incidence angle, ${ }^{\circ} . \sigma$ standard deviation, mrad. $\mathrm{R}$ hemisferical reflectance, $\% . \mathrm{f}(0)$ density of probability in specular direction.

\begin{tabular}{|c|c|c|c|c|c|c|c|c|c|c|c|c|}
\hline \multirow[b]{3}{*}{$\theta$} & \multicolumn{6}{|c|}{ Manufacturer A } & \multicolumn{6}{|c|}{ Manufacturer B } \\
\hline & & Test-1 & & & Test- & & & Test- & & & Test-2 & \\
\hline & $\mathbf{R}$ & $\sigma$ & $f(0)$ & $\mathbf{R}$ & $\sigma$ & $f(0)$ & $\mathbf{R}$ & $\sigma$ & $f(0)$ & $\mathbf{R}$ & $\sigma$ & $f(0)$ \\
\hline- & - & - & - & - & - & - & - & - & - & - & - & \\
\hline 20 & 88.1 & 0.21 & 0.76 & 88.4 & 0.26 & 0.61 & 84.1 & 0.24 & 0.66 & 83.8 & 0.25 & 0.64 \\
\hline 40 & 87.2 & 0.23 & - & 87.5 & 0.27 & - & 83.0 & 0.25 & - & 82.6 & 0.27 & - \\
\hline 60 & 86.2 & 0.22 & - & 86.4 & 0.31 & - & 81.6 & 0.36 & - & 81.2 & 0.28 & - \\
\hline 80 & 86.3 & 0.25 & - & 86.2 & 0.90 & - & 82.6 & 0.78 & - & 82.4 & 0.50 & - \\
\hline
\end{tabular}


Table II. - Specifiable optical parameters for facets.

\begin{tabular}{ll}
$\begin{array}{ll}\text { Factors } \\
\text { Silvered }\end{array}$ & \multicolumn{1}{c}{\begin{tabular}{c}
\multicolumn{1}{c}{ Parameter } \\
Gas a function of the incidence \\
angle
\end{tabular}} \\
Glass & $\begin{array}{l}\sigma \text { longitudinal and transversal } \\
\text { Shape }\end{array}$ \\
& $\begin{array}{l}\sigma \text { adjustment radius and with } \\
\text { respect to nominal }\left(\Delta t=20^{\circ}\right. \\
\left.\text { and } 20 \text { cycles }-30^{\circ} 60^{\circ} \mathrm{C}\right) .\end{array}$
\end{tabular}

length of the surface imperfections and the peak values.

The glass surface is characterized by the standard. deviation on adjusting the beam of actual normal deviations to a normal distribution. The value of the standard deviation defined herein is closely connected to the quality parameters used by the glass manufacturers (wedge angle, optical power, zebra angle, etc.), the definition of that parameter being more practical for solar studies.

4.2.2.2 Interferometry [5]. - By using an interferometer on a mirror sample the attached photographic prints have been obtained. The values obtained are entirely in accordance with those obtained by the mechanical procedures 4.2.2.1. The advantage of the rapidity and its possible use in the field make this method practical and applicable to the required selection of glass for facets in the manufacturing line (Fig. 4).

4.2.3 Shape dispersions. - In addition to the method 4.1 .2 as mentioned before, the use of the mechanical method 4.2.2.1 for dimensions of facets is a practical method for measuring the facet shape.

Once the planimetry of the facet is obtained $(100 \div 200$ points), with an accuracy of $0.01 \mathrm{~mm}$, these values are treated by adjusting them to a theoretical surface (admissible later in calculation programmes) and by defining the deviations of the actual normal ones from the theoretical deviation, thus obtaining a distribution which meets a normal distribution, the parameter of which, standard deviation, is of use to characterize the facet shape.

The characterization process for the shape of a facet is attached (Fig. 5).
Minimum tested mrad

$$
\begin{aligned}
& \sigma=0.21 \\
& \sigma=0.23 \\
& \sigma=0.19 \\
& \sigma=0.49 \\
& \sigma=0.58 \\
& \sigma=1.05 \\
& \sigma=2.30
\end{aligned}
$$

Tentative specific mrad

$$
\begin{aligned}
& 0.20 / 10^{\circ} \\
& 0.23 / 60^{\circ} \\
& 0.15 \text { (long) } \\
& 0.30 \text { (trans) } \\
& 0.40 \text { adjustment } \\
& 0.80 \text { total initial } \\
& 1.50 \text { after cycle }
\end{aligned}
$$

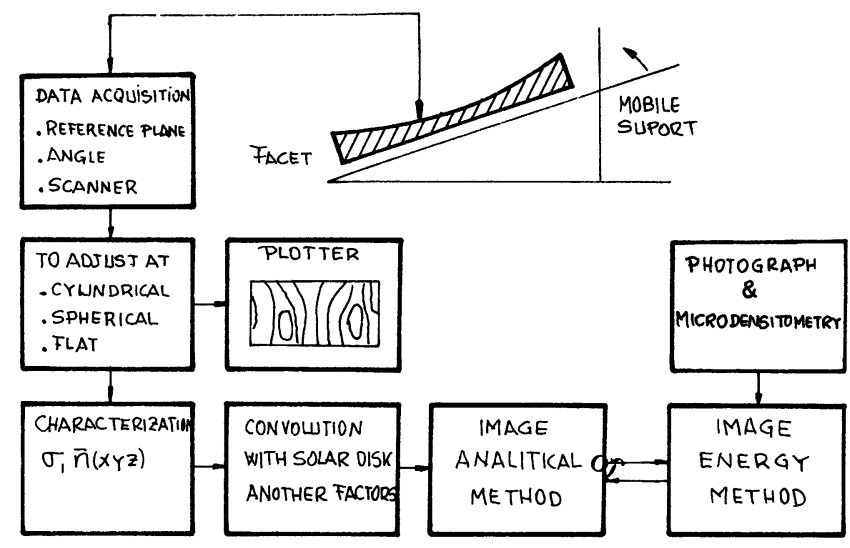

Fig. 5. - Process of shape characterization.

4.3 Specifiable optical parameters. - The above-described tests show the method and parameters which are of use as quality control during the manufacturing of a facet.

The parameters listed above refer to typical unidimensional deviation on the basis of an adjustment to a normal distribution in mrad (Table II).

Conclusion. - The various methods for optical analysis of heliostat facets presented here seem to be a good tool for obtaining a sound specification of facets (analytical methods) and serve as a criteria for the acceptance of heliostat prototypes (energy methods).

All those methods are currently being used with success in the specification as well as testing of the heliostat prototypes of the Spanish solar-power station project (CESA-1).

\section{References}

[1] Biggs, F., Virtitoe, C. N., Sandia Laboratories, Livermore, USA. The Helios Model for the Optical Behavior of Reflecting Solar Concentrators, March 1979.

[2] Goodman, J., Introduction to Fourier Optics. McGraw-Hill. Pag. 149-154.

[3] Petrt, R. B., Sandia Laboratories, Livermore, USA. Characterization of the Reflected Beam Profile of Solar Mirror Materials and Solar Energy 19 № 6 (1977).
[4] Conferencias del I Seminario de Metrologia Dimensional. 1975 Asociación Española de Control de Calidad. Madrid.

[5] Instituto Nacional de Optica, "Montaje Goniofotométrico " (Consejo Superior de Investigaciones Cientificas), Madrid.

[6] INITEC, Energia, Proyecto 5033 CESA, 1 «Estudio de la Reflectancia Especular y Difusa de Espejos de Prototipos de heliostatos ». 1.978, Madrid. 